\title{
Development of bamboo scrimber: a literature review
}

\author{
Yuxiang Huang ${ }^{1}$, Yaohui $\mathrm{Ji}^{2}$ and Wenji Y ${ }^{1 *}$
}

\begin{abstract}
Bamboo fiber-based composite made from crushed bamboo fiber, termed bamboo scrimber, has gained particular interest of researchers and manufacturers on account of its excellent mechanical characteristics and design. This paper reviewed the available literature on the state of the art of bamboo scrimber including the developing history and current production technology of high-performance bamboo scrimber. The results of analytical and experimental investigations illustrate the effects of bamboo species, defibering times, heat treatment, adhesives, densities, etc. on the performance of bamboo scrimber.
\end{abstract}

Keywords: Bamboo scrimber, Bamboo fiber-based composites, Composite processing, Mechanical properties, Factors affecting performance

\section{Introduction}

Recently, with increasing resource demands in today's modern industrialized world, the demand for structural timber products for building materials has increased [1]. However, as the quantity and quality of wood resources from the forest have been declined, it is becoming increasingly necessary to explore opportunities for new building materials instead of traditional utilizations of wood. In addition to similar environmental characteristics such as renewability, biodegradability and carbon sequestration, bamboo has excellent mechanical properties comparable to that of wood and a faster growth rate. As such, it is considered a promising raw material substitute for wood [2]. On the other hand, bamboo is being grown as a plantation besides natural occurrence in many countries such as China and India, which benefits local farmers to improve their lives by processing it into various products [3].

Bamboo is hollow internally producing tubelike parts in between the nodes, where longitudinal fibers are aligned within a lignin matrix (Fig. 1). The thickness of the culm wall tapers from the base of the culm to the

\footnotetext{
*Correspondence: chinayuwj@126.com

${ }^{1}$ Key Laboratory of Wood Science and Technology of State Forestry Administration, Research Institute of Wood Industry, Chinese Academy of Forestry, Xiangshan Road, Haidian District, Beijing 100091, China Full list of author information is available at the end of the article
}

top. The bamboo fibers, characterized by their slender form-long, taped at both ends, and sometimes, forked, also vary within the culm wall decreasing in density from the outer wall to the inner wall. These variations in geometric and mechanical properties limit the full culm bamboo construction in spite of more than 1200 bamboo species all over the world. Moreover, it is difficult to make connections and joints for round sections. Tubes cannot be used in application [4]. With the growing industry and demand for sustainable building products, bamboo is used to produce engineered bamboo composites to standardize the shape and reduce the variability of material properties [5]. Bamboo scrimber, as a new type of engineered bamboo composite, consists of crushed bamboo fiber bundles saturated in resin and pressed into a dense block [6]. This rectangular structural member has outstanding characteristics such as high bamboo utilization ratio (over $80 \%$ ), good grain pattern, similar hardness and color with hardwood, which make it competitive with commonly used building and furniture materials [7-12].

This paper synthesizes state-of-the-art knowledge on the development, processing and the resulting material performance of bamboo scrimber in an effort to consolidate the studies on bamboo scrimber and encourage further development of this material. 


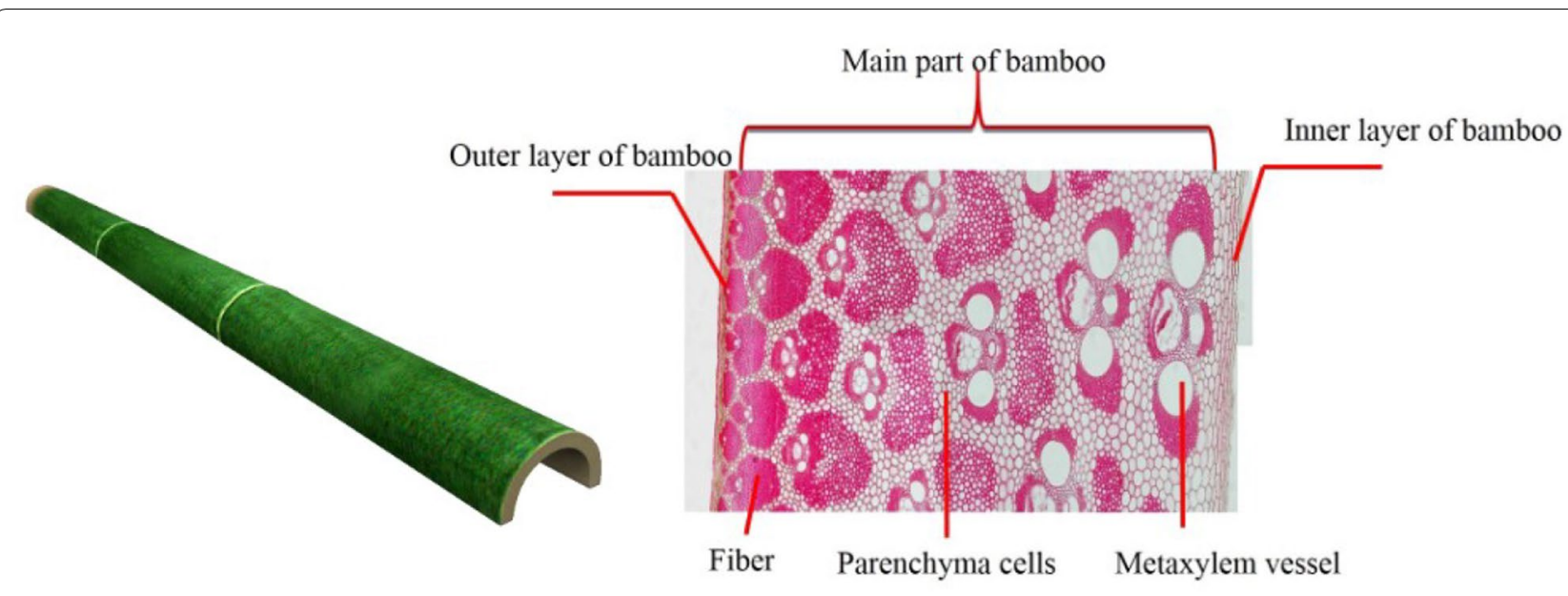

Fig. 1 Details of a bamboo culm

\section{Evolution of bamboo scrimber}

As average log size is diminishing and wood quality is declining, the long and large lumber members needed for commercial construction systems are becoming less available and more expensive. The lower-value trees have been fully utilized to produce wood composite products. "Scrimber," originally proposed by Coleman, has been created where low-quality wood was flattened and split into strands $[13,14]$. Then, the strands are glued and compressed to beams, overcoming the anisotropy of natural lumber and retaining the natural wood texture and the original fiber orientation. Bamboo scrimber, also called recombinant lumber or reconstructed lumber in China and bamboo zephyr board in Japan [1, 15], emerged in the beginning of the 1980s by using small-diameter bamboo culms to make a reconstructed structural material. Originally, bamboo scrimber was developed in a laboratory in China. In 1987, highstrength bamboo scrimber was successfully prepared from bitter bamboo in the laboratory of Nanjing Forestry University [16]. Later, wild miscellaneous bamboo with unused value was used to produce bamboo scrimber in Chinese Academy of Forestry in 1989 [17]. At the beginning of the 1990s, a softening technology was adopted by Nanjing Forestry University and bamboo scrimber without removing the bamboo outer skin was developed [18]. It was not until the late 1990s that the industrial production of bamboo scrimber realized, which should be attributed to the Anji enterprises in Zhejiang. They innovated and produced bamboo scrimber by using cold-pressing equipment. However, compared with wood-based panels, the production technology level and automation level of bamboo scrimber industry were not high. The bamboo outer skin and inner skin were usually removed via planing process or splitting process, and the utilization rate of bamboo was about $50-60 \%$. After more than 10 years' efforts, the Research Institute of wood industry in Chinese Academy of Forestry developed a new generation of bamboo scrimber (also called bamboo-based fiber composite) by using small-diameter scattered bamboo as raw material $[6,7,19-21]$. Long bamboo fiber bundles are extracted directly from bamboo culm using the novel mechanical method without removing the bamboo outer skin and inner skin. This technology is not only suitable for large-diameter moso bamboo, but also for smalldiameter mixed bamboo. The utilization ratio of bamboo increased to more than $90 \%$, which greatly reduced the cost of the production of bamboo scrimber.

\section{Production process of bamboo scrimber}

Originally, in the laboratory test stage, the main production processes of bamboo scrimber included truncation and splitting, softening, removing the bamboo outer skin, defibering, drying, sizing, assembly and hot-pressing. With the continuous progress of technology, some steps have been omitted in the process of large-scale production of bamboo scrimber, where truncation and splitting, defibering, drying, dipping, assembly, cold-pressing and heat curing or hot-pressing are the main processes (Fig. 2).

\section{Truncation and splitting}

The bamboo was cut short according to the dimension of the press. The number of splitting pieces is determined by the diameter of bamboo. The larger the diameter of bamboo, the more the splitting pieces are, since the width of bamboo strips splitting from the bamboo with different diameters is basically the same. 


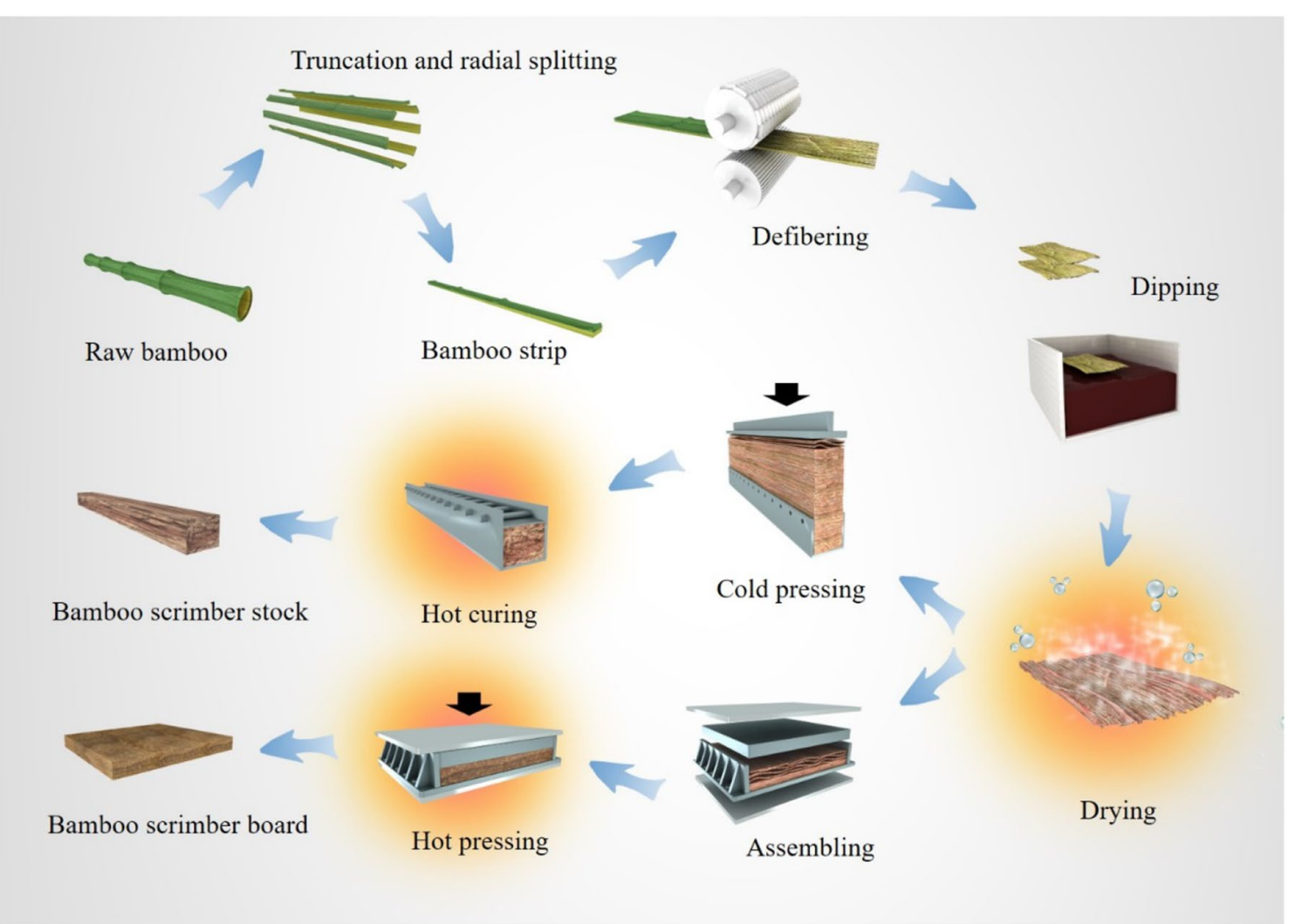

Fig. 2 Process flow diagram of bamboo scrimber

\section{Softening}

The intercellular layer of bamboo could be separated with the lye treatment, which facilitated the defibering process [22]. However, excessive alkalinity significantly affects the physical and chemical properties of bamboo as well as the mechanical properties of bamboo scrimber. A better softening effect could be obtained if bamboo was boiled in $3 \%$ wt. $\mathrm{NaOH}$ or $\mathrm{Na}_{2} \mathrm{CO}_{3}$ solution. The use of chemical reagents increased the cost and pollution; therefore, the softening process was discarded in actual production.

\section{Removing the bamboo outer skin}

The bonding strength between bamboo bundles is weak due to the high oil content in the bamboo outer skin and inner skin. In addition, the bamboo outer skin and inner skin have great influence on the mechanical properties and dimensional stability of bamboo scrimber [23]. Therefore, removing the bamboo outer skin and inner skin is a necessary process to manufacture bamboo scrimber. However, it adds the manufacturing procedure and increases the production cost. In the latest production process developed by Chinese Academy Forestry, the separate process for removing the bamboo outer skin and inner skin is omitted; most of them are removed during the defibering process.

\section{Defibering}

The defibering process is also a preparation of bamboo bundle unit, which is the key link in the production of bamboo scrimber and the main difference between bamboo scrimber and other bamboo-based panels. The early way of defibering was mainly handmade, which was of low efficiency and required high labor intensity [17]. Thus, this way was quickly eliminated. Hereafter, manual hammering and roll-in were adopted to prepare bamboo bundles. The former would cause mechanical damage to bamboo, while the processing conditions could be controlled for the latter. In order to obtain ideal bamboo bundles, it is more difficult to directly use the roll-in method. It is usually necessary to soften the bamboo before rolling. With the continuous technology improvement in equipment, it is no longer necessary to soften the bamboo when preparing the bamboo scrimber. Wang et al. [24] put forward a treatment method of bamboo bundle. After removing the outer skin and splitting, bamboo was rolled into unbroken and loosely interlaced 
bamboo bundles along the direction of bamboo fiber. With the increasingly close cooperation between scientific research institutes and enterprises, the Wood Industry Institute of China, Chinese Academy of Forestry jointly with the related enterprises developed a novel fluffer machine (Fig. 3) [25]. The rollers of the novel machine were composed of several specialshaped gears with intervals between the teeth to make linear-shaped cracks and the driving rollers arrange uniform convex pocks to generate dotted cracks on the bamboo [26]. During this mechanical treatment, most of the outer skin and the inner skin were removed.

\section{Drying}

The moisture content (MC) of bamboo after defibering is above the fiber saturation point. The MC of bamboo bundles needs to be dried below $10 \%$ so that there is room for the resins to get in.

\section{Dipping}

Dipping is also the key process for manufacturing bamboo scrimber, which determines its bonding performance. The resin currently used is the phenolic resin; and the impregnation amount of the resin is controlled by the solid content of the resin, the impregnation method (in vacuum or at normal pressure), the soaking time and the $\mathrm{MC}$ of bamboo units. In actual production, the impregnation is designed according to the requirements of bamboo scrimber's performance and use. For example, if the bamboo scrimber is used for outdoor purpose where high waterproof performance is required, the impregnation could be higher $(>20 \%)$.

\section{Cold-pressing and hot-curing}

After drying the resin-impregnated bamboo bundles to $12-15 \% \mathrm{MC}$, they are directly molded and shaped at high pressure of 70-80 MPa. Then, the mold is locked and sent to the curing channel for resin curing. Cold-pressing process is mainly used for manufacturing the squareedged bamboo scrimber with thickness of $15-18 \mathrm{~cm}$. The commonly used size (length $\times$ width $\times$ thickness) for the square stock is $193 \times 10.5 \times 15.0 \mathrm{~cm}$ or $200 \times 14.5 \times 15.0 \mathrm{~cm}[27]$.

\section{Hot-pressing}

As for hot-pressing, the traditional heat transfer technology by contacting is used to fabricate the slab at a certain temperature. The unit pressure is 4-6 $\mathrm{MPa}$, far below that used for cold-pressing. The commonly used size (length $\times$ width $\times$ thickness) for the bamboo scrimber board is $244 \times 122 \times 1.5-4.0 \mathrm{~cm}$.

Each of the two technologies has advantages and disadvantages. Cold-pressing and heat curing have relatively high production efficiency and low energy consumption. However, due to the need for high pressure, bamboo bundles are easily crushed by machinery, resulting in lower mechanical properties. In addition, the density of bamboo scrimber using cold-pressing technology could reach $1.2 \mathrm{~g} / \mathrm{cm}^{3}$. At such high density, there is a possibility that the resin does not remain on the surface of the bamboo bundles, which leads to starved joints and further reduces the bonding strength.

Although the hot-pressing method has made up the shortage of the cold-pressing to some extent, there are also two problems. On the one hand, the slab needs artificial paving, leading to large diffidence in the density of boards. The maximum density deviation could exceed

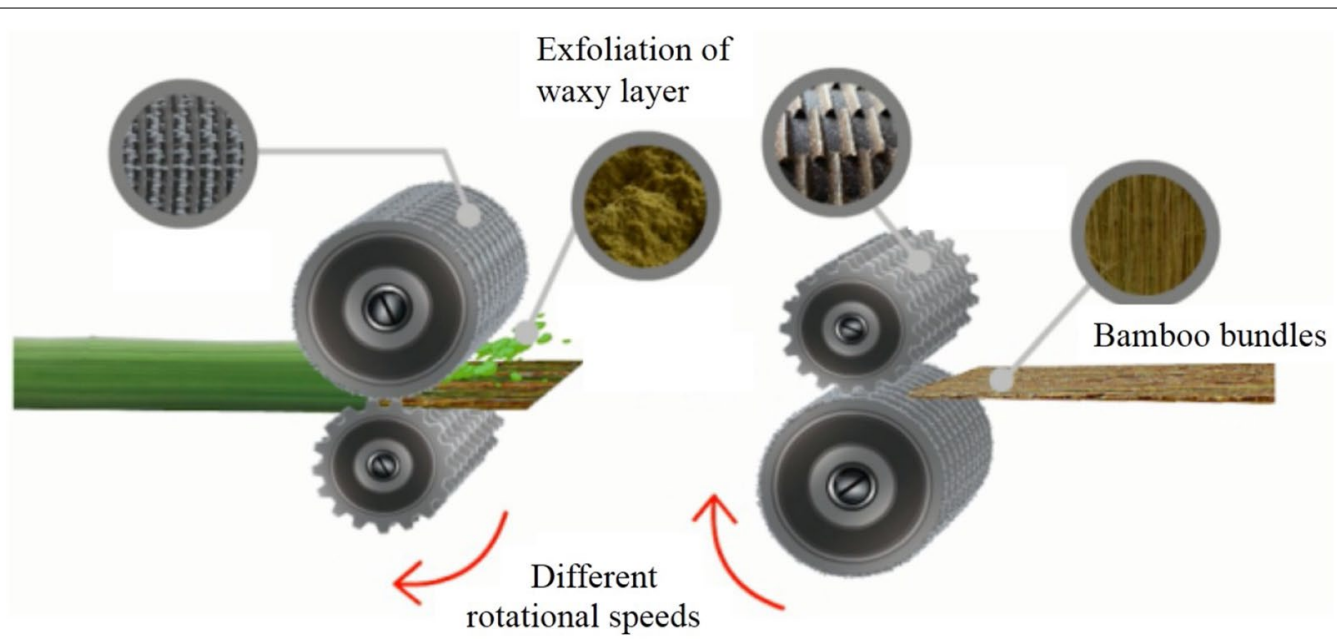

Fig. 3 Schematic diagram of the novel fluffer machine developed by Chinese Academy of Forestry 
$20 \%$. On the other hand, "cold-in and cold-out" process is needed for the hot-pressing technology, which requires large consumption of water and energy, and the hotpressing efficiency is low. Otherwise, it is easy to cause defects such as bubbling.

\section{Performance characteristics of bamboo scrimber}

Bamboo scrimber has the natural ligneous feeling of wood with xylem vessel-shaped fine grooves on the surface (Fig. 4a). Some of the surface textures are straight strip shaped (Fig. 4b), some are mountain shaped (Fig. 4c), and some have a small pattern of vortexes (Fig. 4d), natural and fluent, rich in change. This scrimber material feels similar to wood, warm and smooth.

Bamboo scrimber also has the advantage of processing convenience. The manufacturer can utilize the wood processing equipment and technology to process the bamboo scrimber. The structure of furniture made from bamboo scrimber could combine with each other by the traditional furniture tenon, and the modern connection structure could also be adopted.

In addition to high mechanical performance, bamboo scrimber also has excellent dimensional stability. The thickness swelling rate after $24 \mathrm{~h}$ of water absorption is as low as $0.4 \%$, far lower than the European standard EN13329 (20\%) [28]. The free formaldehyde emission of bamboo scrimber is below $0.4 \mathrm{mg} / \mathrm{L}$, reaching the requirement of ASTM E1333 [29]. It is an essential characteristic that the physical and mechanical properties of bamboo scrimber can be designed via adjusting its structure and manufacturing technology. The densities and mechanical properties of different wood-/bamboo-based composites such as bamboo scrimber [2, 7 , $21,30]$, poplar-based scrimber [31], laminated bamboo lumber (LBL) [2] and laminated veneer lumber (LVL) [32] are summarized in Table 1. As shown in Table 1 the density of bamboo scrimber varies from 0.72 to $1.30 \mathrm{~g} / \mathrm{cm}^{3}$. Correspondingly, the modulus of rupture (MOR) of bamboo scrimber increased from 178.5 to 398.0 MPa, which has more than doubled. The modulus of elasticity (MOE), short-beam strength (SS), tensile strength (TS) and compressive strength (CS) of bamboo scrimber also show overwhelmingly higher than those of other bamboo-based composites.
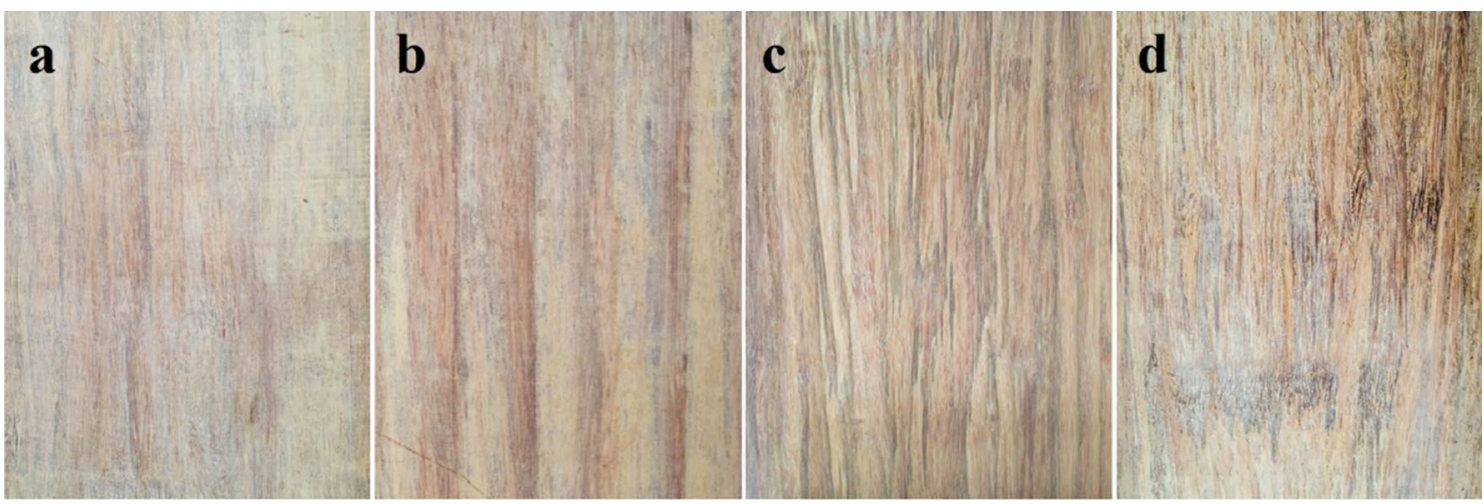

Fig. 4 The surface of bamboo scrimber with different textures (a wood grain; $\mathbf{b}$ strip shaped; c mountain shaped; $\mathbf{d}$ pattern of vortexes)

Table 1 Comparison of density and mechanical performance of bamboo scrimber and other bamboo-/wood-based composites

\begin{tabular}{|c|c|c|c|c|c|c|}
\hline Material & Density $\left(\mathrm{g} / \mathrm{cm}^{3}\right)$ & $\operatorname{MOR}^{a}(\mathrm{MPa})$ & $\operatorname{MOE}^{b}(G P a)$ & $\mathrm{SS}^{\mathrm{C}}(\mathrm{MPa})$ & $\mathrm{TS}^{\mathrm{d}}(\mathrm{MPa})$ & $\mathrm{CS}^{\mathrm{e}}(\mathrm{MPa})$ \\
\hline Bamboo scrimber & $0.72-1.3$ & 178.5-398.0 & $13.5-32.3$ & 18.9-26.2 & $227.6-364.8$ & $70.5-199.3$ \\
\hline Wood scrimber & 1.01 & 142.4 & 19.3 & 14.4 & 97.3 & - \\
\hline $\mathrm{LBL}$ & 0.69 & $77-83$ & $11-13$ & 16 & 90 & 77 \\
\hline LVL & 0.51 & 85.4 & 14.3 & 6.8 & - & - \\
\hline
\end{tabular}

\footnotetext{
a Modulus of rupture

b Modulus of elasticity

c Short-beam strength

d Tensile strength

e Compressive strength
} 


\section{Factors affecting the performance of bamboo scrimber Bamboo species}

There are 75 genera with 1250 bamboo species worldwide, and bamboo properties including anatomical structure and physical-mechanical properties are significantly different with species [33]. The differences in bamboo properties also significantly affect its mechanical or chemical processing procedures and the performance of end products [34]. Xie et al. [35] fabricated bamboo scrimber from five bamboo species (Neosinocalamus affinis, Dendrocalamus farinosus, Phyllostachys heterocycla, Dendrocalamus latiflorus and Bambusa pervariabilis McClure Dendrocalamopsis daii). The smaller fiber lumen diameter of bamboo contributed to lower water absorption of bamboo scrimber, and thicker fiber wall contributed to lower MOR.

\section{Bamboo internode}

According to Qi et al. [30], bamboo scrimber manufactured from bamboo fiber mats without nodes had greater tensile strength, compressive strength, MOE and MOR, while that from bamboo fiber mats with nodes had greater horizontal shear strength.

\section{Defibering times}

The defibering process can remove the waxy and siliceous layers on the surface of bamboo which are difficult to glue. Meanwhile, the bamboo could be separated into some basic tissues including the vascular bundles, ducts and fibers. With increasing the defibering times, more dotted and/or linear-shaped cracks are formed in the culm wall and the diameters of bamboo bundles decrease. This increases the specific surface area of bamboo bundles, which makes it more efficient for adhesives to penetrate and improve the bonding strength of the products. The bamboo scrimber prepared from the bamboo bundles defibered for 7 times (type 1) showed better compression strength, Young's modulus and dimensional stability, compared with that from the bamboo bundles defibered for 5 times (type 2) [19]. However, type 1 displays lower tensile strength because the increase in defibering process leads to the further broking of bamboo fibers. The study by Nugroho and Ando [1] used different numbers of bamboo clumps passed through the rollers to obtain different sizes of bamboo zephyr strands. The results showed that bamboo scrimber had higher mechanical properties in the case of smaller strands. This was because the smaller strands had more bundle sheaths per area than the bigger ones. Test results provided by Deng et al. [36] indicated that the color variation of bamboo could characterize the defibering extent. It was found a rising trend for the lightness as well as red hue and yellow hue with increasing extent of removing the outer skin of bamboo.

\section{Moisture}

As mentioned above, a drying process is required to control the $\mathrm{MC}$ of bamboo fiber mats after defibering. The results provided by Jeang-Kwan and Jong-Bum showed that the mechanical properties decreased with increasing the MC of bamboo fiber mats [37]. Once the MC was above $12 \%, \mathrm{MOR}, \mathrm{MOE}$ and internal bond strength diminished significantly.

\section{Heat treatment}

Heat treatment on bamboo bundles can improve the dimensional stability and biological durability of bamboo scrimber, and deepens its surface color, which is beneficial to its further use in the outdoors. In the case of heat treatment at $200{ }^{\circ} \mathrm{C}$ for $3 \mathrm{~h}$, the thickness swelling rate of bamboo scrimber after $24 \mathrm{~h}$ of water absorption declined by nearly $40 \%$, while its static bending strength declined by $64 \%$ due to the thermal degradation of hemicellulose. In addition to the heat treatment on bamboo bundles, bamboo scrimber is also heat treated with heat conducting oil [38]. When the heating oil temperature and treatment time were $180{ }^{\circ} \mathrm{C}$ and $6 \mathrm{~h}$, respectively, the $24-\mathrm{h}$ thickness swelling rate reached $1.97 \%$, while the MOE and MOR decreased by 28.6 and $31.6 \%$, respectively. Exposure to high temperatures also led to the decrease in mechanical properties of bamboo scrimber, and color changes occurred in the inner and external areas of the samples. As the temperature exceeded $150{ }^{\circ} \mathrm{C}$, the color changes became more apparent. Shangguan et al. [39] found that $170{ }^{\circ} \mathrm{C}$ was a turning point for physical, mechanical and chemical properties of bamboo scrimber under heat treatment condition.

\section{Dye treatment}

In order to broaden the application scope of bamboo scrimber in exterior environments, it needs to be given different colors through proper dyeing techniques in addition to natural color and carbonized color. In a study by $\mathrm{Hu}$ and $\mathrm{Yu}$ [40], bamboo fiber mats were treated with acid black. It was found that the dyeing procedure slightly reduced the MOR and MOE of bamboo scrimber but improved the water repellency. A similar variation trend for mechanical properties and water repellency was found when Basic Brown G dye was used [41].

\section{Adhesives}

Nugroho and Ando [1] reported the results for the thickness swelling of bamboo scrimber using diphenylmethane diisocyanate (MDI) resin. The TS values of bamboo 
scrimber increased with the increase in board density, which could be ascribed to the greater springback of the compacted particles in boards of high density. Contrary to Nugroho and Ando, Xie et al. [35] found that both the width and thickness swelling showed a decrease with the fabricated density when phenolic resins were used. The difference may originate from the different molecular weights of adhesives, which determine the permeability of adhesives in bamboo.

\section{Fire retardant}

As the bamboo scrimber has been more and more applied in building and decoration fields, the chance of fire accident occurrence also increases because bamboo material belongs to combustible material. Nanoparticles $\left(\mathrm{CaCO}_{3}, \mathrm{CaO}, \mathrm{MgCO}_{3}\right.$ and $\left.\mathrm{MgO}\right)$ with a diameter of $5-50 \mathrm{~nm}$ were added into phenolic resin by $\mathrm{Fu}$ et al. [42] to improve the flame-retardant property of bamboo-wood hybrid scrimber. After adding 10\% nanoparticles, each mechanical property of bamboo-wood hybrid scrimber was improved. Their findings were in agreement with the study reported by $\mathrm{Du}$ et al. [43], in which applying $\left(\mathrm{NH}_{4}\right)_{2} \mathrm{HPO}_{4}$ fire retardant before gluing would increase part of physical and mechanical properties of bamboo scrimber. However, it would increase the manufacturing cost.

\section{Method of mat formation}

During the manufacturing process of bamboo scrimber by hot-pressing, the mats are usually formed manually, which is not only of low efficiency but also results in the abrupt fluctuation of the density profile for bamboo scrimber. The study by $\mathrm{He}$ et al. [44] innovated bamboo bundle knitting process in manufacturing of bamboo scrimber. In the study, the bamboo bundles were knitted to consecutive bamboo bundle veneer, which was then laminated and hot-pressed along the grain to manufacture knitted bamboo scrimber. Their results revealed that bamboo bundle knitting process could decrease the thickness swelling and improved shear strength due to more uniform structure and even density profile over the cross section.

\section{Hot-pressing parameters}

Test results provided by Kim et al. [45] indicated that internal bond strength of bamboo scrimber generally increased with increasing temperature. Bamboo scrimber hot-pressed by $160{ }^{\circ} \mathrm{C}$ for $12 \mathrm{~min}$ and $180{ }^{\circ} \mathrm{C}$ for $10 \mathrm{~min}$ exhibited relatively higher wet-bending strength [46].

\section{Density}

According to Kumar et al. [47], all the mechanical properties of bamboo scrimber significantly vary with the density of bamboo scrimber as well as with the fiber orientation. A positive linear relationship was found between density and MOR (or MOE) no matter whether the measurements were done parallel or perpendicular to the fiber direction of bamboo scrimber [48]. As the density increased from 1.02 to $1.3 \mathrm{~g} / \mathrm{cm}^{3}$, the MOR of bamboo scrimber almost increased by $50 \%$, from 271 to $398 \mathrm{MPa}$ and the MOE increased from 26.4 to $32.3 \mathrm{GPa}$ [21]. The water absorption decreased from 43.0 to $5.01 \%$ as the density increased from 0.8 to $1.2 \mathrm{~g} / \mathrm{cm}^{3}$ [35], which could be attributed to the closeness of bamboo lumens such as vessels, parenchymas and fibers caused by highpressure hot-pressing process.

In addition, the rise of density had positive effects on color stability and dimensional stability. Based on service-performance and cost-minimization considerations, $1.1 \mathrm{~g} / \mathrm{cm}^{3}$ was determined as the most appropriate density for general applications [49].

\section{Milling process parameters}

In a study by Wang et al. [50], the effects of milling process parameters on cutting forces and surface roughness were studied during edge cutting of bamboo scrimber. The results showed that decreasing the feed rate appropriately could improve the quality of machined surface roughness and decrease power consumption. In the case of $8 \mathrm{~m} / \mathrm{min}$ feed speed and $1.6 \mathrm{~mm}$ cutting depth, highquality planed surfaces with low roughness of the bamboo scrimber board were obtained [3].

\section{Post-treatment of products}

Li et al. [51] investigated the effect of post-treatments including water immersion, oil immersion, air drying and infrared drying on color changes, dimensional stability and cracking behavior of bamboo scrimber. The results showed that the bamboo scrimber became darker after all treatment conditions, especially the oil treatment and infrared drying. The dimensional stability was more or less affected by the treatment conditions except oil treatment. Furthermore, 4-h air drying at $150{ }^{\circ} \mathrm{C}$ or infrared drying at 100 or $150{ }^{\circ} \mathrm{C}$ led to the cracks of bamboo scrimber. Three standard methods (ASTM D1037, BS EN1087-1 and WCAMA) were used by Chang et al. [52] to achieve the hygrothermal aging of bamboo scrimber. After aging, the brittleness of the bamboo scrimber was enhanced and the bending performance declined.

Outdoor exposure tests on bamboo scrimber were performed by Zhu et al. [53] for 2 years. After 2 years of exposure, the surface color values had a decreasing tendency and a gradual decrease was also found in MOR, $\mathrm{MOE}$ and shear strength of bamboo scrimber as a function of exposure time. 


\section{Application field}

In the initial stage of the development of bamboo scrimber, its target product market is mainly located in the indoor floor. Because of its natural and elegant texture over $1.2 \mathrm{~g} / \mathrm{cm}^{3}$ density, it is welcomed by domestic and foreign consumers. As a result, the consumer market is developing rapidly. With the further cognition of the performance of bamboo scrimber, its application scope has gradually extended to furniture manufacturing (Fig. 5a), decoration (Fig. 5b) and outdoor use (Fig. 5c). Outdoor floor has become one of the highest value-added products.

Bamboo scrimber is also used in building structural materials, platform floor and high-end materials such as wind turbine blades (Fig. 5d). With the continuous development of new technology and new process, the application scope of bamboo scrimber will be wider.

\section{Conclusions}

Bamboo scrimber is a kind of bamboo-based composite product using small-diameter bamboo and bamboo waste as raw material. It has changed the present situation of bamboo-based boards. For example, the types of raw materials are limited and the utilization rate of bamboo is low. Also, it explored a new way for the efficient industrial utilization of small-diameter bamboo. The strength and stiffness of bamboo scrimber are far higher than other wood-/bamboo-based products, making it capable of replacing wood in structural applications. The bamboo scrimber prepared by heat treatment and phenolic resin has certain outdoor resistance to mold and decay. Therefore, bamboo scrimber could be considered for outdoor use such as outdoor flooring, trestle and pavilion to give full play to its advantages of high strength and high abrasion resistance. This could improve the added value of bamboo scrimber products and relieve the concern about the shortage of building structural materials.

\section{Challenges}

1. At present, more than $90 \%$ of enterprises in China are still using bamboo strips as the basic material unit and an extra process is needed to remove the outer skin and inner skin of bamboo strips.

2. There is still a lot of room for improvement in the production technology and equipment such as the uneven mat formation in terms of hot-pressing and automation of the equipment used for cold-pressing.

3. The adhesive cannot be characterized by low cost and high bonding strength at the same time.

4. Many enterprises are poorly managed and produce solely on the basis of experience. The lack of precise and standardized process control results in unstable and variable products.

5. Formal codes and standards have not yet been developed.

\section{Solutions}

The defibering technique discussed in this paper for the development of bamboo scrimber helps resolve challenge
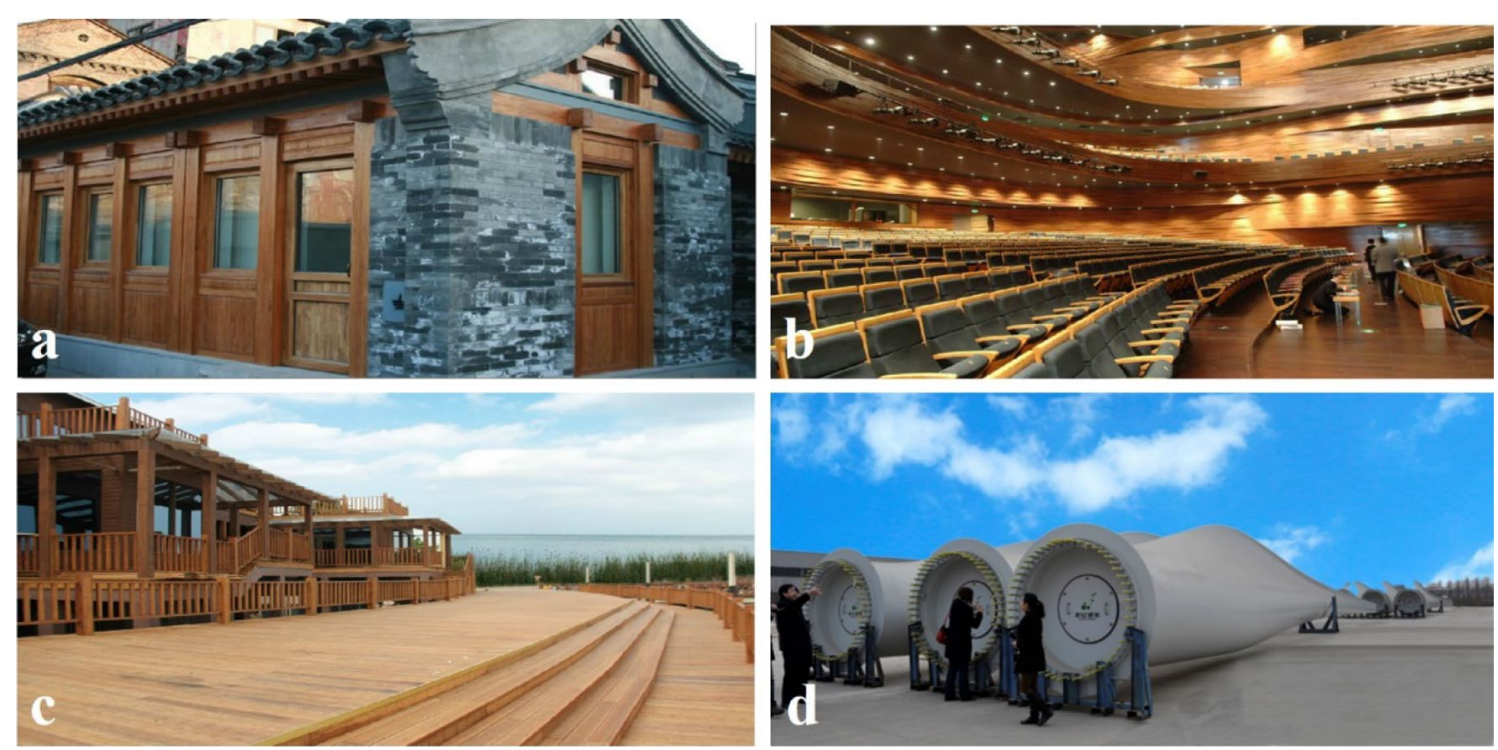

Fig. 5 The application field of bamboo scrimber. a Doors and windows, b interior decoration, c outdoor materials, d wind turbine blade 
1. Challenge 2 will be resolved through improving the degree of mechanical automation of the cold-pressing and hot-pressing production line of bamboo scrimber and developing automatic paving equipment for hot-pressing to improve the labor efficiency. The problems such as high cost, suitable bonding strength and formaldehyde emission could be resolved by developing the modified urea formaldehyde resin and phenolic resin from the formulation and gluing process (challenge 3 ). Challenge 4 will be gradually overcome by formulating operation methods and technical rules for product quality control. Also, strengthening the demonstration work of on-the-spot management and quality control testing helps to solve the problem. Challenge 5 will be resolved via the efforts of researchers and practitioners as further success is seen in their work on this topic.

\section{Abbreviations}

CS: compressive strength; LBL: laminated bamboo lumber; LVL: laminated veneer lumber; MC: moisture content; MDI: diphenylmethane diisocyanate; MOE: modulus of elasticity; SS: short-beam strength; TS: tensile strength.

\section{Acknowledgements}

The authors gratefully acknowledge the financial support from Special Funds for Basic Research and Operating Expenses of Central Level Public Welfare Scientific Research Institutes (CAFYBB2017QA015), Science and Technology Planning Project of Guangdong Province, China (2016B020203002), and Forestry Science and Technology Innovation Project of Guangdong Province, China (2015KJCX031).

\section{Authors' contributions}

YH was a major contributor in writing the manuscript. YJ helped collect relevant information and draw the pictures. WY made substantial contributions to conception and design. All authors read and approved the final manuscript.

\section{Funding}

This work was financially supported by Special Funds for Basic Research and Operating Expenses of Central Level Public Welfare Scientific Research Institutes (CAFYBB2017QA015), Science and Technology Planning Project of Guangdong Province, China (2016B020203002), and Forestry Science and Technology Innovation Project of Guangdong Province, China (2015KJCX031).

\section{Availability of data and materials}

The datasets used and analyzed during the current study are available from the corresponding author on reasonable request.

\section{Ethics approval and consent to participate}

Not applicable.

\section{Competing interests}

The authors declare that they have no competing interests.

\section{Author details}

${ }^{1}$ Key Laboratory of Wood Science and Technology of State Forestry Administration, Research Institute of Wood Industry, Chinese Academy of Forestry, Xiangshan Road, Haidian District, Beijing 100091, China. ${ }^{2}$ College of Materials Science and Technology, Beijing Forestry University, Tsinghua East Road 35, Haidian District, Beijing 100083, China.

Received: 12 January 2019 Accepted: 14 June 2019

Published online: 21 June 2019

\section{References}

1. Nugroho N, Ando N (2000) Development of structural composite products made from bamboo I: fundamental properties of bamboo zephyr board. J Wood Sci 46(1):68-74

2. Sharma B, Gatóo A, Bock M, Ramage M (2005) Engineered bamboo for structural applications. Constr Build Mater 81:66-73

3. Guan M, Cai Z, Zhu Y, Lin J (2012) Performance evaluation of bamboo scrimber under planner machining. Key Eng Mater 517:101-106

4. Mahdavi M, Clouston PL, A.M.ASCE, Arwade SR (2011) Development of laminated bamboo lumber: review of processing, performance, and economical considerations. J Mater Civil Eng 23(7):1036-1042

5. Xiao Y, Yang R, Shang B (2013) Production, environmental impact and mechanical properties of glubam. Constr Build Mater 44:765-773

6. Yu Y, Zhu R, Wu B, Hu Ya YuW (2015) Fabrication, material properties, and application of bamboo scrimber. Wood Sci Technol 49:83-98

7. Yu Y, Huang X, Yu W (2014) A novel process to improve yield and mechanical performance of bamboo fiber reinforced composite via mechanical treatments. Compos Part B Eng 56:48-53

8. Wang X, Wu Z, Wang X, Song S, Cao Y, Ni J, Sun Q, Fei B (2015) Shearing behavior of structural insulated panel wall shelled with bamboo scrimber. Wood Fiber Sci 47(4):336-344

9. Gong Y, Zhang C, Zhao R, Xing X, Ren H (2016) Experimental study on tensile and compressive strength of bamboo scrimber. BioResources 11(3):7334-7344

10. Zhong Y, Wu G, Ren H, Jiang Z (2017) Bending properties evaluation of newly designed reinforced bamboo scrimber composite beams. Constr Build Mater 143:61-70

11. Wu G, Zhong Y, Gong Y, Ren H (2018) Mode II fracture toughness of bamboo scrimber with compact shear specimen. BioResources 13(1):477-486

12. Wei Y, Ji X, Duan M, Li G (2017) Flexural performance of bamboo scrimber beams strengthened with fiber-reinforced polymer. Constr Build Mater 142:66-82

13. Coleman J (1980) Reconsolidated wood product. US Patent 4232067

14. Coleman J (1980) A "reconsolidated" wood for structural purpose. Division of Chem tech CSIRO, Queensland, pp 1-10

15. Nugroho N, Ando N (2001) Development of structural composite products made from bamboo Il: fundamental properties of laminated bamboo lumber. J Wood Sci 47(3):237-242

16. Li Q, Hua X, Qi L (2001) Prospect for re-combined bamboo timber. J Bamboo Res 1:76-80

17. Wang J (1989) Bamboo scrimber - new process and new product. China Wood Ind 5(2):14-18

18. Wang S, Hua Y (1991) Research on manufacturing process of bamboo scrimber. China Wood Ind 5(2):14-18

19. Yu Y, Huang X, Yu W (2014) High performance of bamboo-based fiber composites from long bamboo fiber bundles and phenolic resins. J Appl Polym Sci 131:40371

20. Yu Y, Liu R, Huang Y, Meng F, Yu W (2017) Preparation, physical, mechanical, and interfacial morphological properties of engineered bamboo scrimber. Constr Build Mater 157:1032-1039

21. Yu Y, Huang Y, Zhang Y, Liu R, Meng F, Yu W (2018) The reinforcing mechanism of mechanical properties of bamboo fiber bundle reinforced composites. Polym Compos 40(4):1463-1472

22. Wang S, Hua Y (1994) Effect of softening process variables on reconsolidated bamboo and bamboo itself properties. J Nanjing For Univ. 57-62

23. Ye L, Jiang H (1991) Research on bamboo scrimber board. J Zhejiang For Coll 2:133-140

24. Wang K, Li Q, Hua X, Weng F, He Q (2003) The manufacturing method of the bamboo scrimber based plywood. China Patent CN1387981

25. Yu W, Yu Y, Zhou Y, Ren D (2006) Studies on factors influencing properties of reconstituted engineering timber made from small-sized bamboo. China For Prod Ind 33(6):24-28

26. Yu W (2011) Development of bamboo-fiber based composites. China Wood Ind 25(1):6-8

27. Yu W (2012) Current status and future development of bamboo scrimber industry in China. China Wood Ind 1:11-14

28. EN 13329 (2016) Laminate floor coverings-elements with a surface layer based on aminoplastic thermosetting resins-Specification, requirements and test methods. European committee for standardization 
29. ASTM E1333-14 (2014) Standard test method for determining formaldehyde concentrations in air and emission rates from wood products using a large chamber. American Society for Testing and Materials

30. Qi J, Xie J, Yu W, Chen S (2015) Effects of characteristic inhomogeneity of bamboo culm nodes on mechanical properties of bamboo fiber reinforced composite. J For Res 26(4):1057-1060

31. Zhang Y, Huang Y, Qi Y, Yu W (2018) Novel engineered scrimber with outstanding dimensional stability from finely fluffed poplar veneers. Measurement 124:318-321

32. Wang BJ, Chui YH (2012) Manufacturing of LVL using cost-effective resin impregnation and layup technologies. Wood Sci Technol 46(6):1043-1059

33. Kamruzzaman M, Saha S, Bose A, Islam M (2008) Effects of age and height on physical and mechanical properties of bamboo. J Trop For Sci 20(3):211-217

34. Xie J, Huang X, Qi J, Hse C, Shupe T (2013) Effect of anatomical characteristics and chemical components on microwave-assisted liquefaction of bamboo wastes. BioResources 9(1):231-240

35. Xie J, Qi J, Hu T, Hoop CFD, Hse CY, Shupe TF (2016) Effect of fabricated density and bamboo species on physical-mechanical properties of bamboo fiber bundle reinforced composites. J Mater Sci 51:7480-7490

36. Deng J, Li H, Wang G, Chen F, Zhang W (2015) Effect of removing extent of bamboo green on physical and mechanical properties of laminated bamboo-bundle veneer lumber (BLVL). Eur J Wood Wood Prod 73(4):499-506

37. Roh J-K, Ra J-B (2009) Effect of moisture content and density on the mechanical properties of veneer-bamboo zephyr composites. Forest Prod J 59(3):75-78

38. He W, Song J, Wang T, Li J, Xie L, Yang Y, Wu B, Zhang Q (2017) Effect of heat oil treatment on bamboo scrimber properties. China For Sci Technol 2(5):15-19

39. Shangguan W, Gong Y, Zhao R, Ren H (2016) Effects of heat treatment on the properties of bamboo scrimber. J Wood Sci 62(5):383-391

40. Hu Y, Yu W (2014) Effects of acid dye on the performance of bamboobased fiber composites. BioResources 9(4):6141-6152

41. Hu YA, He M, Zhu RX, Zhang YH, Yu YL, Yu WJ (2016) Influence of dyeing treatment on the performance of bamboo-based fibre composites. J Trop For Sci 28(2):112-120

42. Fu B, Li X, Yuan G, Chen W, Pan Y (2014) Preparation and flame retardant and smoke suppression properties of bamboo-wood hybrid scrimber filled with calcium and magnesium nanoparticles. J Nanomater 2014:1-6
43. Du C, Song J, Chen Y (2014) The effect of applying methods of fire retardant on physical and mechanical properties of bamboo scrimber. Adv Mater Res 1048:465-468

44. He S, Xu J, Wu Z, Yu H, Chen Y, Song J (2018) Effect of bamboo bundle knitting on enhancing properties of bamboo scrimber. Eur J Wood Wood Prod 76(3):1071-1078

45. Kim Y, Roh J, Park S (2003) Effect of zephyr producing method on properties of bamboo zephyr boards. J Korean Wood Sci Technol 31(4):24-30

46. Jung K, Kim Y, Roh J, Park S (2003) Effect of hot-pressing time and temperature on properties of bamboo zephyr boards. J Korean Wood Sci Technol 31(2):77-83

47. Kumar A, Vlach T, Laiblova L, Hrouda M, Kasal B, Tywoniak J, Hajek P (2016) Engineered bamboo scrimber: influence of density on the mechanical and water absorption properties. Constr Build Mater 127:815-827

48. Chung M, Wang S (2017) Mechanical properties of oriented bamboo scrimber boards made of Phyllostachys pubescens (moso bamboo) from Taiwan and China as a function of density. Holzforschung 72(2):151-158

49. Rao F, Chen Y, Li N, Zhao X, Bao Y, Wu Z, Ren D, Xu J, Cai H (2017) Preparation and characterization of outdoor bamboo-fiber-reinforced composites with different densities. BioResources 12(3):6789-6811

50. Wang J, Cao P, Guo X, Xue H, Jia G, Wang B (2015) Effect of process parameters on cutting forces and surface roughness during peripheral up milling of bamboo scrimber. BioResources 10(4):8414-8425

51. Li J, Chen Y, Xu J, Ren D, Yu H, Guo F, Wu Z (2018) The influence of media treatments on color changes, dimensional stability, and cracking behavior of bamboo scrimber. Int J Polym Sci. https://doi. org/10.1155/2018/6068589)

52. Chang X, Wei J, Guan M (2013) Bending performance of carbonized bamboo scrimber and fracture morphology analysis after different ageing treatments. Adv Mater Res 744:362-365

53. Zhu R, Zhang Y, Yu W (2015) Outdoor exposure tests of bamboo-fiber reinforced composite: evaluation of the physical and mechanical properties after two years. Eur J Wood Wood Prod 73(2):275-278

\section{Publisher's Note}

Springer Nature remains neutral with regard to jurisdictional claims in published maps and institutional affiliations.

\section{Submit your manuscript to a SpringerOpen ${ }^{\circ}$ journal and benefit from:}

- Convenient online submission

- Rigorous peer review

- Open access: articles freely available online

- High visibility within the field

Retaining the copyright to your article

Submit your next manuscript at springeropen.com 